\title{
PREDICTION OF DIGESTIBLE ENERGY CONTENT OF EXTRUDED DOG FOOD BY IN VITRO ANALYSES
}

\author{
Hervera M. ${ }^{a}$, Baucells M. ${ }^{a}$, Blanch F. ${ }^{b}$, Castrillo C. ${ }^{\mathrm{c}}$ \\ a Departamento de Ciencia Animal y de los Alimentos, Facultad de Veterinaria, Universitat Autònoma de Barcelona, \\ Cerdanyola, 08193 \\ b Affinity Petcare España \\ c Departamento Producción Animal y Ciencia de los Alimentos, Facultad de Veterinaria, Universidad de Zaragoza, \\ Zaragoza 50013
}

Introduction: Following the NRC (1985), the estimation of energy in pet foods is based on the chemical proximate analysis, assuming constant crude protein (CP), ether extract (EE) and nitrogen free extract (NFE) digestibilities. Recently, factorial equations based on the close relationship existing between the energy digestibility of foods and their crude fiber content have been proposed as good approaches for predicting energy content of food (Kienzle et al., 1998; Castrillo et al., 2001). The aim of this study was to develop a simple and reproducible in vitro method for predicting apparent energy digestibility of dry extruded dog foods.

Material and methods: The proposed method is based on the two-steps multi-enzymatic incubation assay described by Boisen \& Fernández (1991), with some modifications related to time of incubation and enzyme concentration to be adapted to the characteristics of dog's digestion.

The in vitro organic matter disappearance (in vitro dOM) of 44 dry extruded commercial dog foods was determined and used as predictor of the in vivo apparent dMO and energy digestibility (dE) and the digestible energy content (DE). The apparent $\mathrm{dE}$ of all the foods was previously determined by in vivo balances, using 6 female beagles 2-6 years old. In vivo $\mathrm{dOM}$ and $\mathrm{dE}$ of experimental foods ranged from 0.6645 to 0.908 and from 0.6876 to 0.9087 , respectively and their DE content from 3.26 to $4.99 \mathrm{Mcal} / \mathrm{kg}$ $\mathrm{DM}$. The in vivo $\mathrm{dMO}$ and $\mathrm{dE}$ were closely related $(\mathrm{r}=0.969, \mathrm{RSD}=1.36, \mathrm{CV}=1.60 \%)$.

Results and discussion: There was also a close linear relationship between the in vitro and in vivo dMO (In vivo $\mathrm{dMO}, \%)=-5.77+1.025 \times$ (in vitro $\mathrm{dMO}, \%),(\mathrm{r}=0.977, \mathrm{RSD}=1.16, \mathrm{CV}=1.37 \%)$..

The in vitro $\mathrm{dMO}$ explained a 0.90 of the in vivo $\mathrm{dE}(\mathrm{dE} \%=-1.407443+0.97572 \mathrm{x}$ dMO in vitro \%, $\mathrm{r}=0.950, \mathrm{RSD}=1.686, \mathrm{CV}=1.99 \%$ ). As well, a close relationship between the in vivo and predicted $\mathrm{DE}$ (based on in vitro predicted $\mathrm{dE}$ and measured gross energy) was found $(\mathrm{r} 2=0.96, \mathrm{RSD}=0.086, \mathrm{CV}=$ 1.97)). The accurate of DE content prediction using the proposed in vitro method was higher than that obtained when the DE content was predicted from the chemical composition of foods using the digestible energy contents for CP, NFE and EE proposed by the NRC $\left(r^{2}=0.81, \mathrm{CV}=4.67 \%\right)$ and similar than that obtained when using the equations proposed by Castrillo et al. $2001\left(r^{2}=0.87, \mathrm{CV}=3.88 \%\right)$ and Kienzle et al. $1998\left(r^{2}=0.96, C V=2.25 \%\right)$.

Conclusion: The proposed in vitro method provides a more accurate prediction of digestible energy values than the ones proposed by the NRC and FEDIAF, and could be envisage as an alternative system of evaluation of digestible energy content of this kind of foods. Enlarging the number and diversity of food composition (mainly on the fiber fraction) is considered in order to improve the predictive equation.

\section{References:}

Boisen,S.; Fernandez,J.A. Prediction of the total tract digestibility of energy in feedstuffs and pig diets by in vitro analyses. Animal Feed Science and Technology 1997, 68, 277-286.

Castrillo,C.; Vicente,F.; Guada,J.A. The effect of crude fibre on apparent digestibility and digestible energy content of extruded dog foods. Journal of Animal Physiology and Animal Nutrition 2001, $85,231-236$.

Kienzle,E; Opitz,B; Earle,K.E.; Smith,P.M.; Maskell,I.E.,; Iben,C. An Improved Method for the Estimation of Energy in Pet Foods. Journal of Nutrition 1998, 128, 2806S - 2808S.

This study was supported by a research grant from Generalitat de Catalunya and Affinity Petcare España 